\title{
Comparison of standard Maze III and radiofrequency Maze operations for treatment of atrial fibrillation
}

John R. Doty, MD, Donald B. Doty, MD, Kent W. Jones, MD, Jean H. Flores, RN, Marlene Mensah, RN, Bruce B. Reid, MD, Stephen E. Clayson, MD, Greg Snow, PhD, Emily Righter, MS, and Roger C. Millar, MD

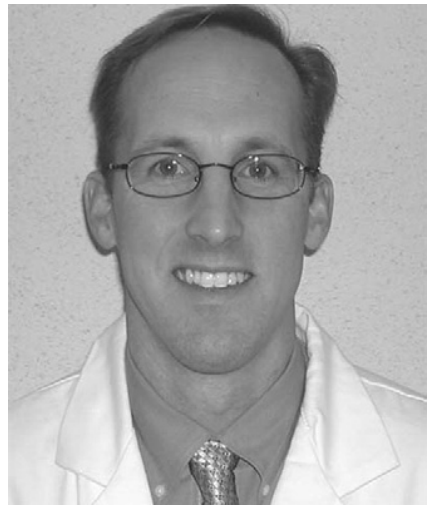

Dr Doty

Objective: This study compares clinical results of the standard Maze III operation, a highly effective treatment for atrial fibrillation, to less complex variations of the Maze III operation utilizing unipolar and bipolar radiofrequency ablation and pulmonary vein isolation.

Methods: Records were reviewed of 377 patients who had operations for treatment of atrial fibrillation at a single institution over a 10-year period. Standard Maze III was performed in 220 patients, unipolar radiofrequency Maze III in 60, bipolar radiofrequency Maze III in 65, and radiofrequency pulmonary vein isolation in 32. Electrocardiograms were obtained at discharge and 3-, 6-, and 12-month intervals. Chi-square test, logistic regression, and Bayesian theory analyses were performed to determine significant associations between operative procedures and outcomes.

Results: Mean age was 65.1 years (range 22-87). There were 13 hospital deaths (3.4\%) and 16 deaths during follow-up. Most patients $(90.2 \%, 340 / 377)$ had concomitant operations. Electrocardiogram analysis was available in 344 patients at 3 months and 313 patients at 6 months. Freedom from atrial fibrillation at 6 months was superior after standard Maze III compared with radiofrequency modifications. Subanalysis according to surgeon experience demonstrated good results regardless of operative experience.

Conclusions: This single-institution experience suggests that the standard Maze III operation is superior to radiofrequency operations for treatment of atrial fibrillation. Radiofrequency modifications of the Maze III operation are also effective treatments for atrial fibrillation and can achieve good results regardless of surgeon experience.

From the Division of Cardiovascular and Thoracic Surgery, LDS Hospital, Salt Lake City, Utah.

Donald Doty reports lecture fees from Medtronic. John Doty reports consulting and lecture fees and grant support from Medtronic. Kent Jones reports consulting and lecture fees from St. Jude. Roger Millar reports consulting fees and grant support from AtriCure.

Received for publication July 5, 2006; revisions received Nov 6, 2006; accepted for publication Dec 7, 2006.

Address for reprints: John R. Doty, MD, Division of Cardiovascular and Thoracic Surgery, LDS Hospital, 324 Tenth Avenue, Suite 154, Salt Lake City, UT 84103 (E-mail: john.doty@intermountainmail.org).

J Thorac Cardiovasc Surg 2007;133:1037-44 $0022-5223 / \$ 32.00$

Copyright (C) 2007 by The American Association for Thoracic Surgery

doi:10.1016/j.jtcvs.2006.12.001

A trial fibrillation affects approximately $1 \%$ of the population of the United States and is a major risk factor for the development of stroke, permanent disability, and death. ${ }^{1,2}$ Over 2 million individuals in the United States and more than 5 million worldwide are estimated to have this disease. ${ }^{3}$ A surgical approach to cure atrial fibrillation was pioneered and refined by Cox and associates. ${ }^{4,5}$ Although technically challenging, the Maze III operation has been demonstrated to be highly effective in restoring a regular rhythm in patients, both for isolated atrial fibrillation and in association with mitral valve disease. ${ }^{6-9}$

Recently, multiple devices have been developed that may potentially provide new methods for performing the Maze III operation. Rather than requiring the surgeon to make multiple incisions on the atria, these devices employ various modalities such as radiofrequency (RF), microwave, laser, or cryoablation energy to create a linear path of injury to the atrial wall. The injury results in scar formation, resulting in the eventual Maze III pathway without the extensive "cut and sew" incisions from the standard Maze III operation. Early results suggest that these devices are effective and can make the operation easier, more efficient, and safer, 


\section{Abbreviations and Acronyms}

$\mathrm{RF}=$ radiofrequency

allowing more surgeons to offer this potentially curative surgery to more patients. ${ }^{10-21}$

This study examines the efficacy of devices employing RF energy to perform modified versions of the Maze III operation in comparison with the standard "cut and sew" Maze III operation. This study was performed at a single institution (LDS Hospital, Salt Lake City, Utah) by a single group of surgeons. The primary end point for analysis and evaluation was the percentage of patients who are free from atrial fibrillation 6 months after surgery.

\section{Materials and Methods}

\section{Data Collection}

A retrospective analysis was performed of all patients in the LDS Hospital surgical database who had an operation for atrial fibrillation. Over a 10-year period, 377 patients underwent surgery for atrial fibrillation, with or without a concomitant operation. Perioperative data collected included date of surgery, operating surgeon, type of operation, gender, age, atrial fibrillation history, cardioversion history, concomitant operation, and rhythm at discharge from the hospital. Follow-up data collected included rhythm at 3 months, 6 months, and then yearly; antiarrhythmic therapy at 3 months, 6 months, and then yearly; and anticoagulant medication.

Preoperative rhythm was categorized as either intermittent or continuous atrial fibrillation according to the classification by Cox. ${ }^{22}$ Patients were stratified into 2 major groups for freedom from atrial fibrillation after operation. Patients in sinus rhythm, paced rhythm, junctional rhythm, or other regular rhythm were considered to be free from atrial fibrillation. Patients with atrial fibrillation, atrial flutter, or other irregular rhythm were considered to be failures of surgical therapy.

\section{Operative Techniques}

Standard Maze III operation. The surgical technique for the standard Maze III operation has been previously described. ${ }^{4}$ Surgical incisions were made without variation from the original technique, and $-70^{\circ} \mathrm{C}$ cryoablation lesions were placed on the coronary sinus, the posterior mitral annulus, and two sites on the tricuspid valve annulus. The right atrial incisions were performed prior to aortic occlusion and arrest of the heart via cold retrograde blood cardioplegia for the left atrial incisions.

Unipolar RF Maze III modification. The surgical technique for the modification of the Maze III operation using a unipolar RF device is illustrated in Figure 1. The Medtronic Cardioblate irrigated unipolar RF system (Medtronic, Inc, Minneapolis, Minn) was used for all patients having this operation. The left atrial appendage was excised, and atrial incisions were limited to an oblique incision on the right atrium, a vertical incision in the right atrial appendage, and a standard left atriotomy. The remainder of the Maze III lesions were created on the endocardial surface using the unipolar pen. No cryoablation was employed.

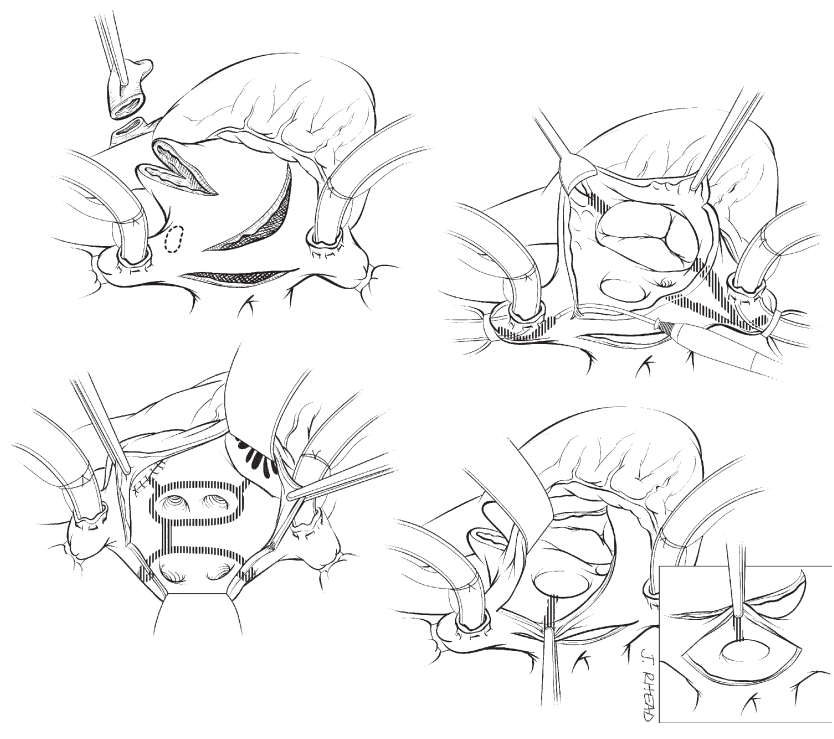

Figure 1. Unipolar RF modification of Maze III operation. The left atrial appendage is excised, and atrial incisions are limited to an oblique incision on the right atrium, a vertical incision in the right atrial appendage, and a standard left atriotomy. The remainder of the Maze III lesions are created on the endocardial surface using the unipolar pen. $R F$, radiofrequency.

Bipolar RF Maze III modification. The surgical technique for the modification of the Maze III operation using a bipolar RF device is illustrated in Figure 2. Two devices were used for patients having this operation: the Medtronic Cardioblate BP irrigated bipolar RF system (Medtronic, Inc) and the AtriCure nonirrigated bipolar RF system (AtriCure, Inc, Cincinnati, Ohio). As with the unipolar modification, the left atrial appendage was excised, and atrial incisions were limited to an oblique incision on the right atrium, a vertical incision in the right atrial appendage, and a standard left atriotomy. The remainder of the Maze III lesions were created by clamping the atrial wall between the electrodes of the bipolar device. In areas where the bipolar device could not be placed across the atrial wall, such as the atrial septum, the coronary sinus, or near the mitral and tricuspid annulus, either the unipolar $\mathrm{RF}$ pen or $-70^{\circ} \mathrm{C}$ cryoablation lesions were used to complete the lesions. Right atrial inferior isthmus ablation was performed when Cardioblate BP was employed but not with AtriCure.

$\boldsymbol{R} \boldsymbol{F}$ pulmonary vein isolation. The surgical technique for pulmonary vein isolation using a bipolar RF device is illustrated in Figure 3. Two devices were used for patients having this operation: the Medtronic Cardioblate BP irrigated bipolar RF system (Medtronic, Inc) and the AtriCure nonirrigated bipolar RF system (AtriCure, Inc). The left atrial appendage was excised to remove a potential source of embolization. The right and left pulmonary veins were dissected free, and an RF lesion was created by placing $1 \mathrm{arm}$ of the device on the left atrial wall behind the pulmonary veins and $1 \mathrm{arm}$ on the atrial wall in front of the pulmonary veins. A connecting lesion between the left atrial appendage and the left pulmonary vein encircling lesion completed the procedure. No cryoablation was employed. 


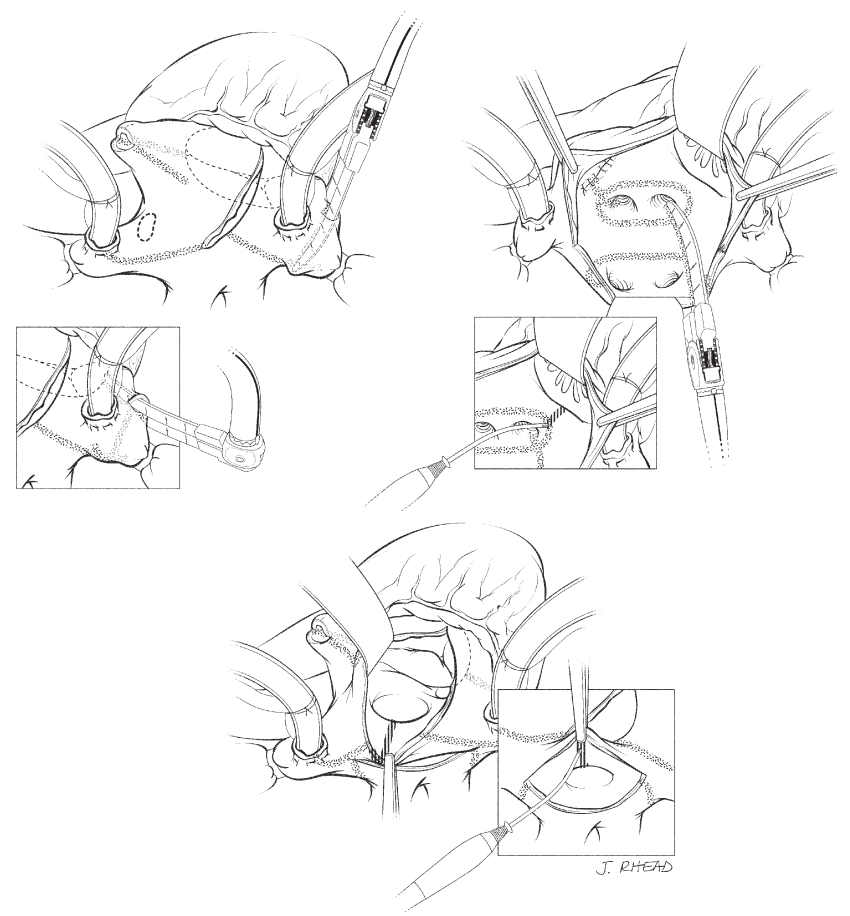

Figure 2. Bipolar RF modification of the Maze III operation. As with the unipolar modification, the left atrial appendage is excised, and atrial incisions are limited to an oblique incision on the right atrium, a vertical incision in the right atrial appendage, and a standard left atriotomy. The remainder of the Maze III lesions are created by clamping the bipolar device across the atrial wall. In areas where the bipolar device cannot be placed across the atrial wall, such as the atrial septum or near the mitral and tricuspid annulus, either the unipolar pen or $-70^{\circ} \mathrm{C}$ cryoablation lesions are used to complete the lesions. $R F$, radiofrequency.

\section{Concomitant Operations}

Additional procedures, such as cardiac valve operations, coronary artery bypass, aortic root replacement, and reconstruction of the ascending aorta, were performed as indicated. Portions of these operations and the Maze III operations were done in a logical sequence during surgery.

\section{Postoperative Management}

Postoperative intensive care and general recovery care were administered in identical fashion to standard care for patients recovering from cardiac surgery. Temporary pacing wires were placed on all patients and used as indicated. Antiarrhythmic medications and anticoagulants were not routinely used. Such medications were employed with recurrence of atrial fibrillation or in the setting of mechanical valve prostheses or multiple valve replacement.

\section{Statistical Analysis}

Chi-square tests were performed to test the null hypothesis that freedom from atrial fibrillation rates were the same among proce-

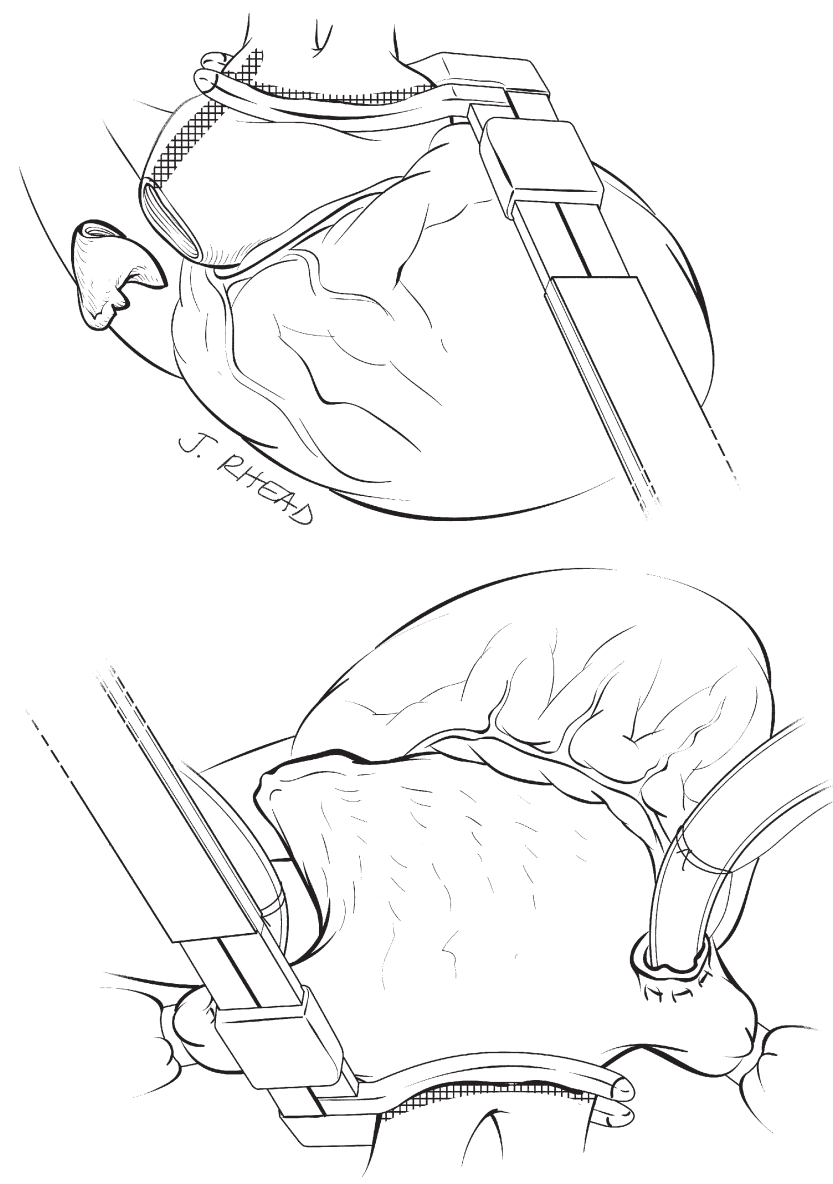

Figure 3. RF pulmonary vein isolation. The left atrial appendage is excised to remove a potential source of embolization. The right and left pulmonary veins are dissected free, and an RF lesion is created by placing $1 \mathrm{arm}$ of the device on the atrial wall behind the pulmonary veins and $1 \mathrm{arm}$ on the atrial wall in front of the pulmonary veins. A connecting lesion between the left atrial appendage and the left pulmonary vein encircling lesion completes the procedure. $R F$, radiofrequency.

dures. Multiple logistic regression analysis was performed to control for additional factors that were also associated with freedom from atrial fibrillation. Odds ratios of the various RF Maze procedures compared with the standard procedure are reported along with their $95 \%$ confidence intervals. Bayesian multiple logistic regression using the Metropolis-Hastings Algorithm was also employed using 100,000 iterations. For the Bayesian analysis, each logistic regression coefficient was initially assumed to be distributed normal with mean 0 , and standard deviation was set to 0.2. The Bayesian analysis generated the probability distribution for the freedom from atrial fibrillation rate for each procedure and provided greater confidence in analysis where numbers of data points were small. Overlapping distributions support the conclusion that freedom from atrial fibrillation rate was not different among the procedures. 
TABLE 1. Summary of patient demographics and preoperative variables

\begin{tabular}{|c|c|c|c|c|}
\hline & Standard Maze III & Unipolar RF Maze III & Bipolar RF Maze III & RF pulmonary vein isolation \\
\hline $\mathrm{n}$ & 220 & 60 & 65 & 32 \\
\hline \multirow[t]{2}{*}{ Gender } & $120 \mathrm{M}$ & $31 \mathrm{M}$ & $35 \mathrm{M}$ & $14 \mathrm{M}$ \\
\hline & $100 \mathrm{~F}$ & $29 \mathrm{~F}$ & $30 \mathrm{~F}$ & $18 \mathrm{~F}$ \\
\hline Mean age, y (range) & $62.5(31-82)$ & $69.3(38-87)$ & $67.3(43-85)$ & $70.5(22-87)$ \\
\hline \multicolumn{5}{|l|}{ Atrial fibrillation history } \\
\hline Continuous & 145 & 45 & 44 & 9 \\
\hline Intermittent & 75 & 15 & 21 & 23 \\
\hline \multicolumn{5}{|l|}{ Cardioversion history } \\
\hline Percutaneous ablation & 17 & 1 & 4 & 1 \\
\hline Chemical cardioversion & 21 & 5 & 10 & 8 \\
\hline Electrical cardioversion & 23 & 14 & 6 & 0 \\
\hline Chemical + electrical & 24 & 12 & 3 & 3 \\
\hline \multicolumn{5}{|l|}{ Concomitant operation } \\
\hline MVR & 27 & 4 & 7 & 2 \\
\hline Mitral valve repair & 17 & 5 & 9 & 3 \\
\hline MVR + tricuspid valve repair & 12 & 0 & 4 & 0 \\
\hline Mitral repair + tricuspid repair & 21 & 6 & 7 & 0 \\
\hline CAB & 12 & 5 & 2 & 7 \\
\hline $\mathrm{CAB}+$ valve operation & 32 & 15 & 20 & 10 \\
\hline Other & 64 & 24 & 15 & 10 \\
\hline Reoperation & 11 & 3 & 6 & 6 \\
\hline
\end{tabular}

$R F$, Radiofrequency; $M V R$, mitral valve replacement; $C A B$, coronary artery bypass.

\section{Results}

Three hundred seventy-seven patients had surgery for atrial fibrillation over a 10 -year period; mean age was 65.1 years (range 22-87). There were 200 male and 177 female patients. Standard Maze III operation was performed in 220 patients, unipolar RF Maze III in 60, bipolar RF Maze III in 65 , and RF pulmonary vein isolation in 32. Most patients $(90.2 \%, 340 / 377)$ had concomitant operations, most commonly isolated or multiple valve procedure $(52.8 \%)$, combined coronary artery bypass and valve procedure (19.1\%), or isolated coronary artery bypass $(7.2 \%) ; 32$ patients needed reoperation $(8.5 \%)$. Preoperative data are summarized in Table 1.

The indication for Maze III operation was continuous atrial fibrillation in $64.5 \%(\mathrm{n}=243)$ and intermittent atrial fibrillation in $35.5 \%(\mathrm{n}=134)$. In the standard Maze III group, indication for surgery was continuous atrial fibrillation in $65.9 \%(\mathrm{n}=145)$ and intermittent atrial fibrillation in $34.1 \%(\mathrm{n}=75)$. In the unipolar RF Maze III group, indication for surgery was continuous atrial fibrillation in $75.0 \%$ $(\mathrm{n}=45)$ and intermittent atrial fibrillation in $25.0 \%(\mathrm{n}=$ 15). In the bipolar RF Maze III group, indication for surgery was continuous atrial fibrillation in $67.7 \%(\mathrm{n}=44)$ and intermittent atrial fibrillation in $32.3 \%(\mathrm{n}=21)$. In the RF pulmonary vein isolation group, indication for surgery was continuous atrial fibrillation in $28.1 \%(\mathrm{n}=9)$ and intermittent atrial fibrillation in $71.9 \%(\mathrm{n}=23)$. Slightly less than half $(42.2 \%)$ of patients had had no attempt at cardioversion prior to surgery. Only 29 (7.7\%) had previously had successful cardioversion to sinus rhythm prior to surgery; the remainder had various unsuccessful electrical, chemical, and percutaneous ablative attempts at cardioversion.

There were 13 hospital deaths (3.4\%): 3 in the standard Maze III group (1.5\%), 4 in the unipolar RF Maze III group (5.0\%), 1 in the bipolar RF Maze III group (1.5\%), and 5 in the RF pulmonary vein isolation group $(15.6 \%)$. Causes of death included cardiac failure in 5, multisystem organ failure in 3 , respiratory failure in 2 , sepsis in 2 , and ischemic bowel in 1 . There was no statistical difference in hospital mortality among the groups.

Stroke or other neurologic event occurred in 3 patients: 1 patient in the standard Maze group and 2 in the bipolar RF modification group. All 3 patients died as a result of the cerebrovascular event. The patient in the standard Maze group had a massive embolic stroke 3 weeks after concomitant aortic valve replacement with a porcine bioprosthesis, mitral valve anuloplasty, and coronary artery bypass grafting. This patient was in sinus rhythm and was adequately anticoagulated on oral warfarin therapy at the time of the stroke. The first patient in the bipolar RF group suffered an intraoperative stroke during a third reoperation for concomitant mitral valve replacement with a mechanical prosthesis and coronary artery bypass grafting. This patient had some recovery but died 5 months after surgery from complications related to neurologic impairment. The second patient in the bipolar RF group became comatose 2 weeks after a third reoperation for concomitant aortic valve 
TABLE 2. Summary of 3-month and 6-month freedom from atrial fibrillation according to operative technique

\begin{tabular}{|c|c|c|c|c|c|}
\hline & Standard Maze III, n (\%) & Unipolar RF Maze III, n (\%) & Bipolar RF Maze III, n (\%) & RF pulmonary vein isolation (n) & $P$ \\
\hline \multicolumn{6}{|l|}{ Time } \\
\hline $3 \mathrm{mo}$ & $190 / 210(90.5)$ & $33 / 50(66.0)$ & $32 / 59(54.2)$ & $18 / 25$ & $<.0001$ \\
\hline $6 \mathrm{mo}$ & $175 / 194(90.2)$ & $33 / 46(71.7)$ & $43 / 54(79.6)$ & $16 / 19$ & .0078 \\
\hline
\end{tabular}

$R F$, radiofrequency.

replacement and mitral valve replacement with bioprostheses, coronary artery bypass grafting, and tricuspid anuloplasty. This patient remained in atrial fibrillation after surgery and was anticoagulated on intravenous heparin. Imaging studies were consistent with brain stem demyelination, and support was withdrawn.

Eight patients were lost to follow-up; follow-up was $98 \%$ complete. Mean length of follow-up was 23 months (range 2 days to 119 months). Permanent pacemaker implantation was required in $39(10.3 \%)$ patients. Pacemaker implantation was most common in the bipolar RF Maze III group $(20.0 \%)$ and least common in the RF pulmonary vein isolation group (6.3\%). Requirement for permanent pacemaker implantation was similar for the standard Maze III group $(8.1 \%)$ and the unipolar RF Maze III group (10.0\%).

There were 16 additional deaths during follow-up: 4 in the standard Maze III group, 6 in the unipolar RF Maze III group, 4 in the bipolar RF Maze III group, and 3 in the RF pulmonary vein isolation group. Cause of late death was not possible to determine reliably from death certificate information.

Electrocardiogram analysis was available in 344 patients at 3 months and 313 patients at 6 months (Table 2). Standard chi-square test and pairwise comparisons without regard for confounding variables were first performed to determine significant associations between operative procedures and outcomes. Freedom from atrial fibrillation at 3 months was better after standard Maze III compared with other procedures $(P<.0001)$. At 6 months, freedom from atrial fibrillation remained superior after standard Maze III compared with other procedures $(P=.0078)$.

Multiple logistic regression controlling for confounding variables was then performed on the data for the entire patient cohort to identify variables affecting outcomes after each form of the Maze III operation (Table 3). After controlling for

TABLE 3. Summary of logistic regression analysis of freedom from atrial fibrillation at 6 months according to procedure, as compared to standard Maze III operation

\begin{tabular}{lccc}
\hline & $\begin{array}{c}\text { Odds } \\
\text { ratio }\end{array}$ & $\boldsymbol{P}$ & $\begin{array}{c}\text { 95\% confidence } \\
\text { interval }\end{array}$ \\
\hline Unipolar RF Maze III & 0.28 & $<.0001$ & $0.12-0.61$ \\
Bipolar RF Maze III & 0.42 & .047 & $0.19-0.96$ \\
Pulmonary vein isolation & 0.58 & .559 & $0.15-2.17$ \\
\hline
\end{tabular}

$R F$, radiofrequency. confounding variables, freedom from atrial fibrillation after the standard Maze III operation was statistically superior to unipolar RF Maze III and bipolar RF Maze III operations. Freedom from atrial fibrillation after RF pulmonary vein isolation was statistically equivalent to standard Maze III operation. There was no statistical difference among the $3 \mathrm{RF}$ modifications of the Maze III operation.

Further exploration of the variables was performed using Bayesian theory. Subanalysis was performed according to operating surgeon, identified by number. Figure 4 illustrates the distribution of procedures by each surgeon. Surgeon \#1 had the most experience with unipolar RF Maze III. Surgeon \#2 had the most experience with the standard Maze III operation, bipolar RF Maze III, and RF pulmonary vein isolation. Figure 5 illustrates the probability distribution for freedom from atrial fibrillation rate for each procedure. The standard Maze III operation has the best freedom from atrial fibrillation, but the probability distributions overlap for all of the procedures. Figure 6 illustrates surgeon \#2's outcomes for freedom from atrial fibrillation in patients undergoing surgery for atrial fibrillation. Again, freedom from atrial fibrillation was best with the standard Maze III operation in this surgeon's experience, but the probability distributions overlap for all of the procedures. Figure 7 illustrates the combined outcomes of the other surgeons with less experience in patients having surgery for atrial fibrillation. Freedom from atrial fibrillation was also superior in these surgeons' experience with the standard Maze III op-

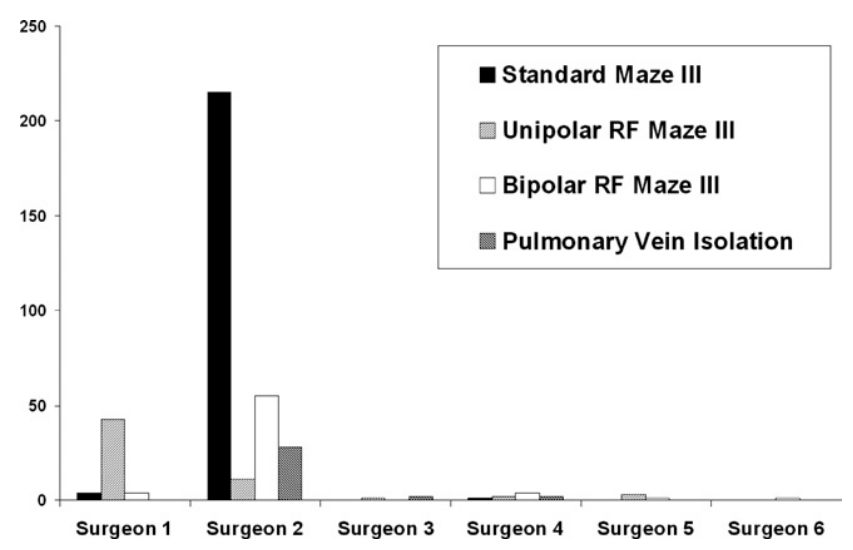

Figure 4. Distribution of procedures according to operating surgeon. $R F$, radiofrequency. 


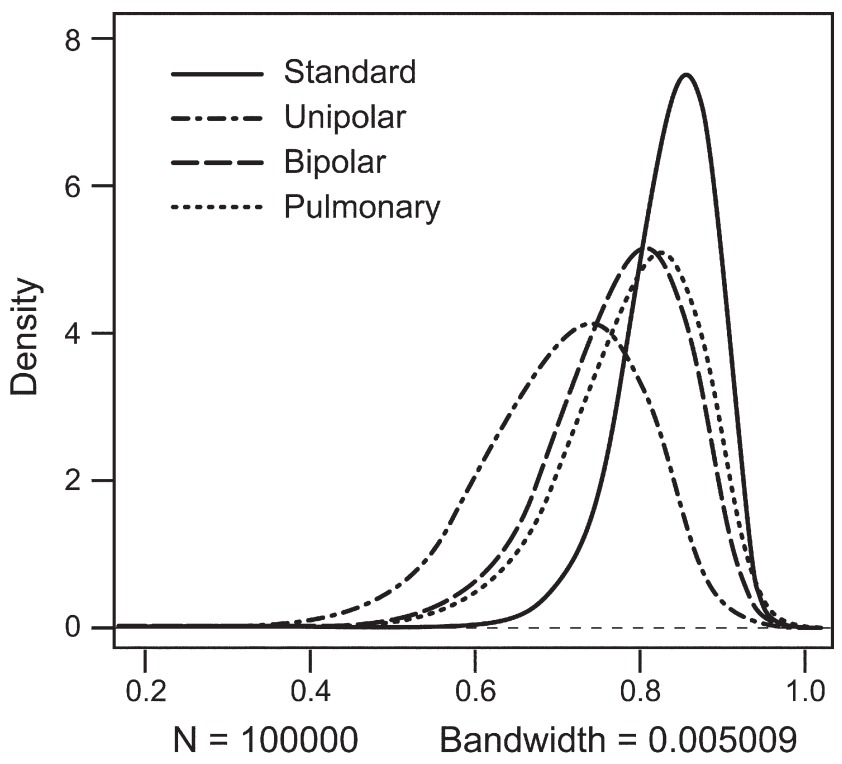

Figure 5. Bayesian analysis for probability of freedom from atrial fibrillation for all surgeons by operation at 100,000 iterations. Standard Maze III operation has the greatest freedom from atrial fibrillation but is not statistically different from RF modifications. $R F$, radiofrequency.

eration, and the probability distributions overlap. Regardless of type of operation or surgeon experience, freedom from atrial fibrillation after any form of RF operations was not different from standard Maze III operation.

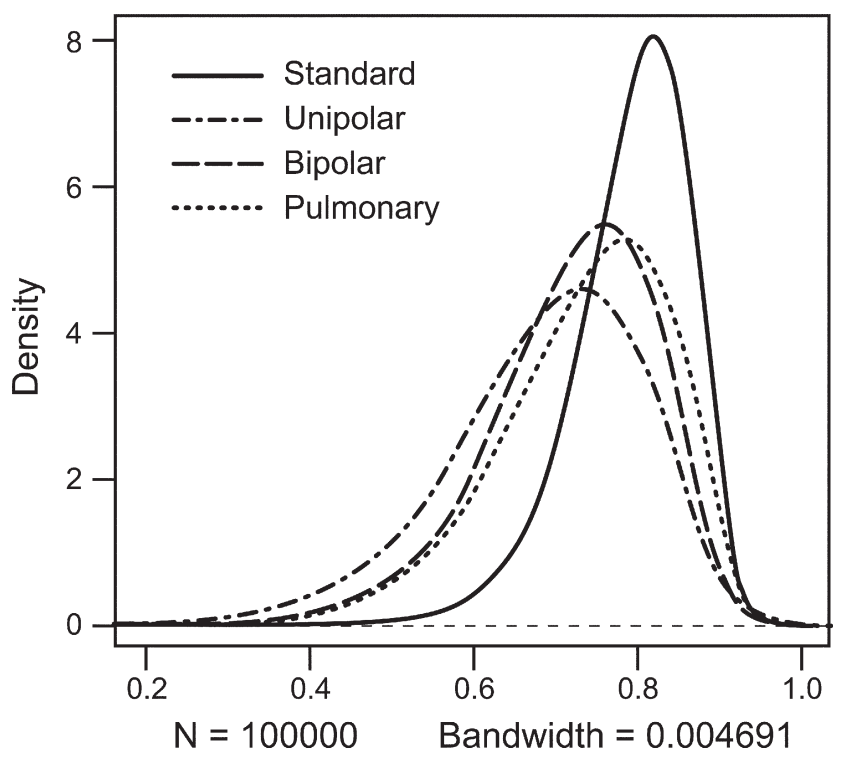

Figure 6. Bayesian analysis for probability of freedom from atrial fibrillation for the single most experienced surgeon by operation at $\mathbf{1 0 0 , 0 0 0}$ iterations. Standard Maze III operation has the greatest freedom from atrial fibrillation but is not statistically different from $R F$ modifications. $R F$, radiofrequency.

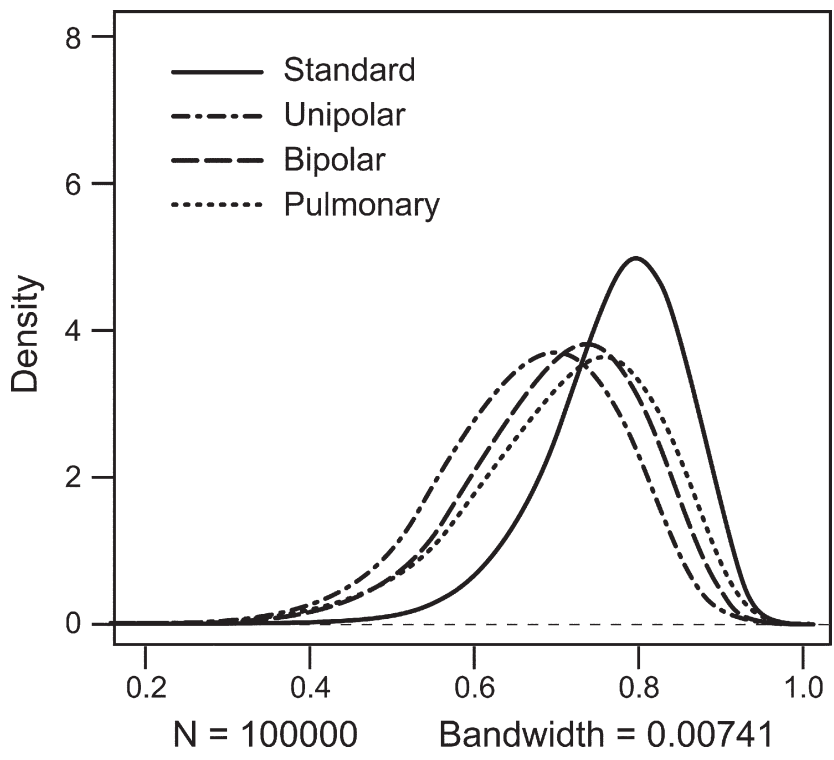

Figure 7. Bayesian analysis for probability of freedom from atrial fibrillation for all other surgeons by operation at 100,000 iterations. Standard Maze III operation has the greatest freedom from atrial fibrillation but is not statistically different from RF modifications. $R$, radiofrequency.

Information on antiarrhythmic therapy was available for 263 patients. Antiarrhythmic therapy was determined by each patient's internist or cardiologist, was variable according to individual physician practice, and could be unrelated to presence or absence of atrial fibrillation. The majority of these patients $(219,83.3 \%)$ were taking no antiarrhythmic medications. Most of the remaining patients $(29,11.0 \%)$ were maintained on amiodarone.

Information on anticoagulation therapy was available for 284 patients. Anticoagulation was determined by each patient's internist or cardiologist, was variable according to individual physician practice, and could be unrelated to presence or absence of atrial fibrillation. Of these patients, $86(30.1 \%)$ were on no anticoagulation, $106(37.3 \%)$ were on aspirin only, and 92 (32.4\%) were on warfarin therapy.

\section{Discussion}

The Maze III operation has become the standard surgical approach for the treatment of atrial fibrillation, with low mortality and cure rates approaching $90 \%$ of patients in sinus rhythm as reported by multiple authors. ${ }^{6-9}$ Despite these excellent results, the "cut and sew" Maze III operation has not been widely adopted. The operation is technically challenging and time-consuming, and many surgeons are reluctant to add such a lengthy procedure to operations that may already include valve and/or coronary artery bypass procedures. In addition, the general perception of the med- 
ical community is that atrial fibrillation is not a particularly dangerous condition and can be safely managed with anticoagulation and cardiac rate control rather than subject a patient to an additional procedure during cardiac surgery.

This study demonstrates that RF modifications of the Maze III operation can be performed with equivalent mortality to the standard Maze III operation. More importantly, these modified operations produce high cure rates for atrial fibrillation. Other investigators have previously reported good success rates with unipolar endocardial or epicardial RF ablation techniques. ${ }^{23-25}$ Although there was no statistically significant difference between the 3 types of RF operations in this study, the bipolar RF Maze III operation had the highest freedom from atrial fibrillation. This rate was essentially identical to that of the standard Maze III operation and is similar to that reported by Gillinov and colleagues ${ }^{26}$ It is important to note that RF modifications of the Maze III operation will typically not result in immediate restoration of sinus rhythm, or even within short-term follow-up. ${ }^{15}$ As demonstrated by this series of patients, however, the full effect of RF Maze III surgery can be reliably measured at the 6-month interval, when full development of atrial scar has occurred.

Bipolar RF ablation should result in the most thorough linear scar, as transmurality of the lesion is assured when there is loss of conduction across the atrial tissue. Unipolar RF ablation, although effective in this cohort of patients, probably is less effective at producing a transmural lesion, particularly in thick atrial tissue. ${ }^{27}$ It is our preference to reserve use of unipolar RF ablation for the isolated portions of the Maze III operation where the bipolar device cannot be applied safely or effectively, including the atrial septum, where fat in the intra-atrial groove impedes transmission of energy and where care must be taken to avoid injuring the valve leaflet tissue near the mitral and tricuspid annuli, and when crossing the left atrial isthmus to prevent injury to the coronary sinus or the left circumflex coronary artery. In all these locations, the atrial wall is thin and transmural ablation can be safely accomplished using unipolar application of energy. Unipolar RF ablation is also useful in the setting of reoperation where complete dissection of the heart is either impossible or risky due to extensive adhesions.

RF pulmonary vein isolation has recently been described as an effective modality for treatment of atrial fibrillation and was confirmed in this study as well. ${ }^{28,29}$ However, the number of patients having pulmonary vein isolation was relatively small compared with the other 3 groups of patients and had a higher percentage of patients with intermittent atrial fibrillation. We do not recommend employing pulmonary vein isolation as the sole treatment of atrial arrhythmias, except in patients with paroxysmal/intermittent atrial fibrillation where probability of trigger sites located in the pulmonary veins is high. Pulmonary vein isolation does not treat trigger sites located in areas of the atria or septum, resulting in right-sided atrial arrhythmias, including atrial flutter, which most commonly originates from the right atrial isthmus. ${ }^{30}$ Again, the higher mortality in this group of patients should be considered in light of the relatively small number of patients in this particular series.

Control of operative technique is nearly impossible in any clinical series. Operations tend to evolve somewhat over time, and ability to perform the operation generally improves with experience. Of particular interest in this study, therefore, is the comparison of outcomes between the surgeon with the most experience and those with less experience in arrhythmia surgery. All surgeons were able to obtain good results with all forms of the Maze III operation, and the curves for the RF modifications are essentially identical for the surgeon with the most experience and the surgeons with less experience. This suggests that good results with the RF Maze III operations can be obtained by most surgeons, regardless of previous experience with the standard "cut and sew" Maze III operation.

The current study has several limitations that should be considered. First, recurrence of atrial fibrillation may occur at intervals between clinical follow-up and may not be identified with surveillance electrocardiography. The true incidence of recurrence of atrial fibrillation in this patient cohort may therefore be underestimated. Second, the exact cause of recurrence of atrial fibrillation in each patient is not known, as few patients had postoperative electrophysiologic evaluation. Without such evaluation, the source and location of such failures, such as conduction gap or failed interruption of reentry, is unknown. Last, postoperative antiarrhythmic therapy was not standardized but rather variable according to individual surgeon and referring physician practice. Such variability does not allow for adequate analysis of true freedom from atrial fibrillation without the use of antiarrhythmic therapy.

In conclusion, analysis of this series of patients demonstrates that RF modifications of the Maze III operation can be performed with equivalent mortality and success in curing atrial fibrillation when compared with standard Maze III operation. The RF modifications achieve a Maze III operation efficiently and safely, regardless of an individual surgeon's prior experience with the standard Maze III operation. The RF operations allow more surgeons to apply this technology to a broader range of patients, thereby offering treatment to a greater number of individuals with atrial fibrillation.

\section{References}

1. Hylek EM, Go AS, Chang Y, Jensvold NG, Henault LE, Selby JV, et al. Effect of intensity of oral anticoagulation on stroke severity and mortality in atrial fibrillation. $N$ Engl J Med. 2003;349:1019-26.

2. Van Gelder IC, Hagens VE, Bosker HA, Kingma JH, Kamp O, Kingma $\mathrm{T}$, et al. Rate Control versus Electrical Cardioversion for 
Persistent Atrial Fibrillation Study Group. A comparison of rate control and rhythm control in patients with recurrent persistent atrial fibrillation. $N$ Engl J Med. 2002;347:1834-40.

3. Feinberg WM, Blackshear JL, Laupacis A, Kronmal R, Hart RG. Prevalence, age distribution, and gender of patients with atrial filbrillation. Arch Intern Med. 1995;155:469-73.

4. Cox JL, Schuessler RB, D'Agostino HJ Jr, et al. The surgical treatment of atrial fibrillation. III. Development of a definitive surgical procedure. J Thorac Cardiovasc Surg. 1991;101:569-83.

5. Cox JL, Jaquiss RD, Schuessler RB, Boineau JP. Modification of the Maze procedure for atrial flutter and atrial fibrillation. II. Surgical technique of the Maze III procedure. J Thorac Cardiovasc Surg. 1995;110:485-95.

6. Prasad SM, Maniar HS, Camillo CJ, Schuessler RB, Boineau JP, Sundt TM 3rd, et al. The Cox Maze III procedure for atrial fibrillation: long-term efficacy in patients undergoing lone versus concomitant procedures. J Thorac Cardiovasc Surg. 2003;126:1822-8.

7. Damiano RJ Jr, Gaynor SL, Bailey M, Prasad S, Cox JL, Boineau JP, et al. The long-term outcome of patients with coronary disease and atrial fibrillation undergoing the Cox Maze procedure. J Thorac Cardiovasc Surg. 2003;126:2016-21.

8. Arcidi JM Jr, Doty DB, Millar RC. The Maze procedure: the LDS Hospital experience. Semin Thorac Cardiovasc Surg. 2000;12:38-43.

9. Millar RC, Arcidi JM Jr, Alison PJM. The Maze III procedure for atrial fibrillation: should the indications be expanded? Ann Thorac Surg. 2000;70:1580-6.

10. Benussi S, Nascimbene S, Agricola E, Calori G, Calvi S, Caldarola A, et al. Surgical ablation of atrial fibrillation using the epicardial radiofrequency approach: mid-term results and risk analysis. Ann Thorac Surg. 2002;74:1050-6; discussion 1057.

11. Chiappini B, Martin-Suarez S, LoForte A, Arpesella G, Di Bartolomeo R, Marinelli G. Cox/Maze III operation versus radiofrequency ablation for the surgical treatment of atrial fibrillation: a comparative study. Ann Thorac Surg. 2004;77:87-92.

12. Gillinov AM, McCarthy PM. Atricure bipolar radiofrequency clamp for intraoperative ablation of atrial fibrillation. Ann Thorac Surg. 2002;74:2165-8; discussion 2168.

13. Khargi K, Deneke T, Haardt H, Lemke B, Grewe P, Muller KM, et al. Saline-irrigated, cooled-tip radiofrequency ablation is an effective technique to perform the Maze procedure. Ann Thorac Surg. 2001;72: S1090-5.

14. Gillinov AM, McCarthy PM. Alternative energy sources for atrial fibrillation. Ann Thorac Surg. 2004;77:1134.

15. Gillinov AM, Blackstone EH, McCarthy PM. Atrial fibrillation: current surgical options and their assessment. Ann Thorac Surg. 2002;74: 2210-7.

16. Maessen JG, Nijs JF, Smeets JL, Vainer J, Mochtar B. Beating-heart surgical treatment of atrial fibrillation with microwave ablation. Ann Thorac Surg. 2002;74:S1307-11.
17. Williams MR, Knaut M, Berube D, Oz MC. Application of microwave energy in cardiac tissue ablation: from in vitro analyses to clinical use. Ann Thorac Surg. 2002;74:1500-5.

18. Damiano RJ Jr. Alternative energy sources for atrial ablation: judging the new technology. Ann Thorac Surg. 2003;75:329-30.

19. Viola N, Williams MR, Oz MC, Ad N. The technology in use for the surgical ablation of atrial fibrillation. Semin Thorac Cardiovasc Surg. 2002;14:198-205.

20. Schuetz A, Schulze CJ, Sarvanakis KK, Mair H, Plazer H, Kilger E, et al. Surgical treatment of permanent atrial fibrillation using microwave energy ablation: a prospective randomized clinical trial. Eur J Cardiothorac Surg. 2003;24:475-80; discussion 480.

21. Williams MR, Argenziano M, Oz MC. Microwave ablation for surgical treatment of atrial fibrillation. Semin Thorac Cardiovasc Surg. 2002;14:232-7.

22. Cox JL. Atrial fibrillation I: a new classification system. J Thorac Cardiovasc Surg. 2003;126:1686-92.

23. Mohr FW, Fabricius AM, Falk V, Autschbach R, Doll N, Von Oppell $\mathrm{U}$, et al. Curative treatment of atrial fibrillation with intraoperative radiofrequency ablation: short-term and midterm results. $J$ Thorac Cardiovasc Surg. 2002;123:919-27.

24. Raman J, Ishikawa S, Storer MM, Power JM. Surgical radiofrequency ablation of both atria for atrial fibrillation: results of a multicenter trial. J Thorac Cardiovasc Surg. 2003;126:1357-66.

25. Sie HT, Beukema WP, Elvan A, Ramdat Misier AR. Long-term results of irrigated radiofrequency modified Maze procedure in 200 patients with concomitant cardiac surgery: six years experience. Ann Thorac Surg. 2004;77:512-6; discussion 516-7.

26. Gillinov AM, McCarthy PM, Blackstone EH, Pettersson G, Calhoun $\mathrm{R}$, Sabik JF, et al. Bipolar radiofrequency to ablate atrial fibrillation in patients undergoing mitral valve surgery. Heart Surg Forum. 2004;7: E147-52.

27. Thomas SP, Guy DJ, Boyd AC, Eipper VE, Ross DL, Chard RB. Comparison of epicardial and endocardial linear ablation using handheld probes. Ann Thorac Surg. 2003;75:543-8.

28. Kistler PM, Sanders P, Fynn SP, Stevenson IH, Hussin A, Vohra JK, et al. Electrophysiological and electrocardiographic characteristics of focal atrial tachycardia originating from the pulmonary veins: acute and long-term outcomes of radiofrequency ablation. Circulation. 2003;108:1968-75.

29. Tsai CF, Tai CT, Chen SA. Pulmonary vein ablation: role in preventing atrial fibrillation. Curr Opin Cardiol. 2003;18:39-46.

30. Schmieder S, Ndrepepa G, Dong J, Zrenner B, Schreieck J, Schneider MA, et al. Acute and long-term results of radiofrequency ablation of common atrial flutter and the influence of the right atrial isthmus ablation on the occurrence of atrial fibrillation. Eur Heart J. 2003;24: 956-62. 